\title{
Spirometric reference values for Malagasy adults aged $18-73$ years
}

\author{
Julia Ratomaharo ${ }^{1,7}$, Olinto Linares Perdomo ${ }^{2,7}$, Dave S. Collingridge ${ }^{3}$, \\ Rabezanahary Andriamihaja ${ }^{4}$, Matthew Hegewald ${ }^{2,5}$, Robert L. Jensen ${ }^{2,5}$, \\ John Hankinson ${ }^{6}$ and Alan H. Morris ${ }^{2,5}$
}

\author{
Affiliations: \\ ${ }^{1}$ Service de Pneumologie, Hôpital Privé d'Athis-Mons, Athis-Mons, France. \\ ${ }^{2}$ Pulmonary and Critical Care Division, Dept of Medicine, Intermountain Medical Center, Murray, UT, USA. \\ ${ }^{3}$ Office of Research, Intermountain Healthcare, Salt Lake City, UT, USA. \\ ${ }^{4}$ Service de Pneumologie, Centre Hospitalier Universitaire de Toamasina, Toamasina, Madagascar. \\ ${ }^{5}$ University of Utah, School of Medicine, Salt Lake City, UT, USA. \\ ${ }^{6}$ Hankinson Consulting, Inc., Athens, GA, USA. \\ ${ }^{7}$ Both authors contributed equally.
}

Correspondence: Olinto Linares Perdomo, Pulmonary/Critical Care Division, Sorenson Heart and Lung Center, 6th Floor, Intermountain Medical Center, 5121 South Cottonwood Street, Murray, UT 84157-7000, USA. E-mail: Olinto.linares@imail.org

ABSTRACT The American Thoracic Society (ATS) and European Respiratory Society (ERS) recommend that spirometry prediction equations be derived from samples of similar race/ethnicity. Malagasy prediction equations do not exist. The objectives of this study were to establish prediction equations for healthy Malagasy adults, and then compare Malagasy measurements with published prediction equations.

We enrolled 2491 healthy Malagasy subjects aged 18-73 years (1428 males) from June 2006 to April 2008. The subjects attempted to meet the ATS/ERS 2005 guidelines when performing forced expiratory spirograms. We compared Malagasy measurements of forced expiratory volume in $1 \mathrm{~s}$ (FEV1), forced vital capacity (FVC) and FEV1/FVC with predictions from the European Community for Steel and Coal (ECSC), the third National Health and Nutrition Examination Survey (NHANES III) and the ERS Global Lung Function Initiative (GLI) 2012 study.

A linear model for the entire population, using age and height as independent variables, best predicted all spirometry parameters for sea level and highland subjects. FEV1, FVC and FEV1/FVC were most accurately predicted by NHANES III African-American male and female, and by GLI 2012 black male and black and South East Asian female equations. ECSC-predicted FEV1, FVC and FEV1/FVC were poorly matched to Malagasy measurements.

We provide the first spirometry reference equations for a healthy adult Malagasy population, and the first comparison of Malagasy population measurements with ECSC, NHANES III and GLI 2012 prediction equations.

@ERSpublications

Malagasy linear regression predicts spirometry, as do NHANES III and GLI 2012 black and South East Asian equations http://ow.ly/DvUQv

\footnotetext{
This article has supplementary material available from erj.ersjournals.com

Received: June 242014 | Accepted after revision: Oct 102014 | First published online: Nov 132014

Support statement: This work was supported by Pneumalga (Association des pneumologues d'origine malgache, exerçant en France (Association of Malagasy Pulmonologists working in France); Antony, France), the Intermountain Research and Medical Foundation (Murray, UT, USA), and Intermountain Healthcare (Salt Lake City, UT, USA).

Conflict of interest: None declared.
}

Copyright OERS 2015 


\section{Introduction}

The American Thoracic Society (ATS) and the European Respiratory Society (ERS) recommend that reference (prediction) values for pulmonary function tests be obtained from "normal" or "healthy" subjects with similar race/ethnic characteristics wherever possible [1]. In the USA, the ATS-recommended equations are derived from the third National Health and Nutrition Examination Survey (NHANES III) [2]. The NHANES III prediction equations make a clear separation between three subject groups: Caucasian, African-American and Mexican-American. In Europe, the European Community for Steel and Coal (ECSC) reference equations are the most commonly used [3]. The recent ERS Task Force Global Lung Function Initiative (GLI) study 2012 established global spirometric prediction equations for 395-year-olds [4,5] using the GAMLSS (generalized additive models for location, scale and shape) approach [6,7]. These reference equations are intended to be applied globally across all ethnic groups, both sexes and for ages from 3 to 95 years, although different groups have different age ranges. The GLI 2012 study produced the first multi-ethnic, continuous spirometric prediction equations, and lower/upper limits, for four ethnic groups: Caucasian, Black, South East Asian and North East Asian. Subjects not included in these four ethnic groups were included in "others", with predictions derived from the average of the four ethnic groups. Note that GLI 2012 black subjects are equivalent to African-Americans because data for GLI 2012 black subjects were taken exclusively from the USA population samples for the Multi-Ethnic Study of Atherosclerosis (MESA) lung study [8], NHANES III [2], NHANES IV [9] and the study by WANG et al. [10]. The GLI 2012 study investigators exerted an extraordinary effort collecting selected data from 33 countries around the world, but had no data from Madagascar $[4,5]$.

Madagascar is a developing country, where respiratory diseases represent a major public health problem. The Malagasy population of 22 million is composed primarily of Austronesian immigrants from Borneo and black (primarily Bantu) immigrants from Africa. Malagasy, a language of Malaysian roots, is spoken, written and understood in the whole island by the Malagasy population. Because of economic hardship, many people have moved to the cities to find jobs. Poverty-based malnutrition is a large public health problem. The majority of Austronesian immigrants live in the High Plateau $(1370 \mathrm{~m}$ altitude; highland dwellers) where the weather is temperate and most earn their living through manual labour. The majority of black African immigrants live on the coast (coast dwellers) where the weather is tropical and most earn their living by fishing. The black African immigrant population is not comparable to the African-American group in NHANES III with regard to developmental aspects (nutrition, environment, etc.). Currently, $\sim 60 \%$ of the Malagasy population live in the High Plateau (Merina, Betsileo, Vakinankaratra and Sihanaka people) and 40\% live on the coast (Betsimisaraka, Sakalava, Tanala, Tsimihety, Antesaka, Antemoro, Antandroy, Vezo, Bara, Antambahoaka, Antanosy, Mahafaly, Masikoro, Antefasy, Bezanozano and Antakarana people). Currently, about $45 \%$ of the population are aged $<20$ years and only $3 \%$ are $>65$ years. The mean life expectancy is 66.3 years (females 68 years, males 66 years) [11].

Malagasy spirometry prediction equations have not been previously established. The appropriateness of using published prediction equations for other populations to predict Malagasy values has not been evaluated. We intended to: 1) establish spirometric prediction equations for healthy Malagasy adults aged 18-73 years, and 2) compare our Malagasy measurements with predictions from the ECSC [3], NHANES III [2] and GLI 2012 study [4].

\section{Methods}

Subjects and testing procedure

We trained four teams of investigators (general practitioner physicians) in Antananarivo, Madagascar's capital city. We first conducted a workshop focused on chronic obstructive pulmonary disease, asthma, airway obstruction reversibility and lung restriction. In a subsequent workshop we explained the multicentre study intended to account for ethnicity and the lifestyle of the population. We trained the investigators to obtain spirograms with the ZAN100 electronic spirometer, a variable impedance pneumotachometer (EMO International, La Rochelle, France). The general practitioner investigators delivered the questionnaire and performed a chest auscultation for each potential subject.

We sampled 2491 healthy, life-long nonsmoking, non-obese, male and female adult subjects (aged 18-73 years) without a history of respiratory disease (fig. 1). We derived the subject sample from 20 groups in Madagascar: Merina, Betsileo, Vakinankaratra, Sihanaka, Betsimisaraka, Sakalava, Tanala, Tsimihety, Antesaka, Antemoro, Antandroy, Vezo, Bara, Antambahoaka, Antanosy, Mahafaly, Masikoro, Antefasy, Bezanozano and Antakarana. We recruited subjects in the market places, at church after Catholic and Protestant religious services, at companies processing newly hired workers who were required to take medical examinations, among friends and family members of hospitalised patients, and during several "Day of the Breath" events, special events widely advertised by local newspapers, television and radio in Madagascar. 


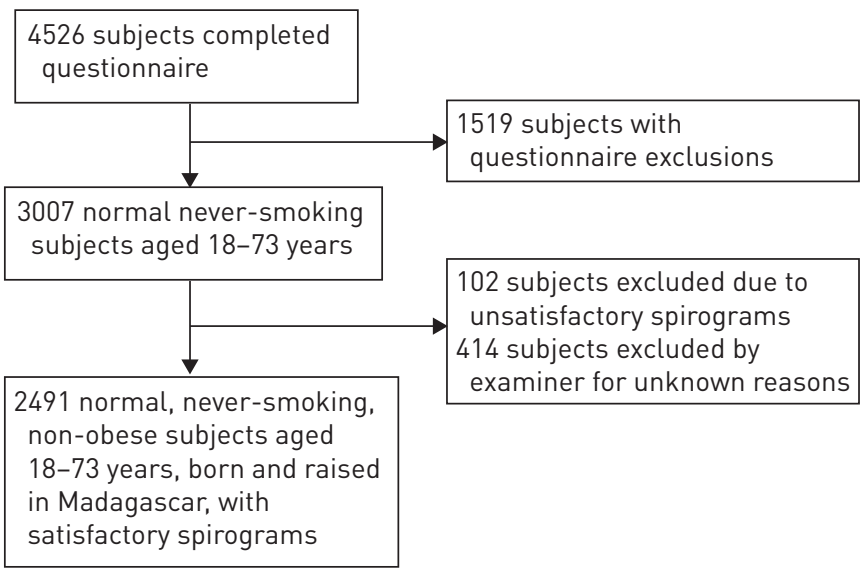

FIGURE 1 Flow diagram of subjects included and excluded, drawn using the CONSORT (Consolidated Standards of Reporting Trials) template.

Subjects attempted to meet the ATS/ERS 2005 guidelines [1] when performing forced expiratory spirograms using the ZAN100 electronic spirometer. We provided the same spirometry method training to all four medical teams in two coastal and two highland (1370 m altitude) centres in Madagascar. We calibrated the spirometers at least daily with a 3-L syringe.

The Malagasy Ethics Committee of the Malagasy Public Health Dept approved the study. Subjects provided informed consent and the following information: age, sex, smoking history, respiratory symptoms, respiratory disease, hypertension, hospitalisation and medication (for the questionnaire, see the online supplementary material). Subjects were excluded if they had respiratory symptoms or disease, any history of smoking, were obese or had malnutrition (body mass index $<18.5$ or $>28 \mathrm{~kg} \cdot \mathrm{m}^{-2}$ ). Minority inhabitants of non-Malagasy origin were excluded (Chinese, Creole, Indian and French).

On the day of examination we measured standing height and weight without shoes with the subjects wearing light clothing. A minimum of three forced expiratory spirograms were obtained for each subject (in a sitting position). We measured forced expiratory volume in $1 \mathrm{~s} \mathrm{(FEV1),} \mathrm{forced} \mathrm{vital} \mathrm{capacity} \mathrm{(FVC),}$ peak expiratory flow (PEF), forced expiratory flows at $25 \%, 50 \%$ and $75 \%$ of exhaled FVC (FEF $25 \%$, FEF50\% and FEF75\%, respectively), and the forced expiratory flow at $25-75 \%$ of exhaled FVC (FEF $25-75 \%$ ).

\section{Statistical analysis}

We used a multiple linear regression model to estimate the median and lower limit of normal (LLN) for FEV1, FVC, FEV1/FVC, PEF, FEF25\%, FEF50\%, FEF75\% and FEF25-75\%. We compared our Malagasy measured values with predicted values from the ECSC [3], NHANES III [2] and GLI 2012 study [4, 5]. We computed the mean of individual subject differences (percentage of measured value) between measured and predicted values. Z-scores were calculated as (observed-predicted)/sDpred, where sDpred is the

\begin{tabular}{lcc}
\hline \multicolumn{1}{l}{ TABLE 1 Demographic data for Malagasy subjects } & \\
& Males & Females \\
\hline Subjects $\mathbf{n}$ & 1428 & 1063 \\
Height cm & $166.4 \pm 6.4(145-198)$ & $155.8 \pm 5.4(138-178)$ \\
Weight kg & $62.4 \pm 8.1(43-87)$ & $54.3 \pm 6.7(39-85)$ \\
Overall age years & $40 \pm 14.13(18-79)$ & $37.6 \pm 13.8(18-79)$ \\
Age group years & & \\
$18-20$ & $80(6)$ & $90(8)$ \\
$21-25$ & $165(12)$ & $160(15)$ \\
$26-29$ & $190(13)$ & $116(11)$ \\
$30-39$ & $322(22)$ & $256(24)$ \\
$40-49$ & $283(20)$ & $209(20)$ \\
$50-59$ & $233(16)$ & $147(14)$ \\
$60-69$ & $124(9)$ & $67(6)$ \\
$70-79$ & $31(2)$ & $18(2)$ \\
\hline
\end{tabular}

Data are presented as mean \pm SD (range) or $\mathrm{n}(\%)$, unless otherwise stated. 
standard deviation of the predicted value. SDpred $=($ predicted-LLN $) / 1.6445$. We compared Z-scores for ECSC [3], NHANES III [2] and GLI 2012 [4, 5] predictions. We only report FVC, FEV1 and FEV1/FVC in this article, because they are the most clinically useful. For analyses of other parameters see the online supplementary material.

We used the R Project for Statistical Computing, version 2.11.1 (www.r-project.org), and MATLAB version R2013b (MATLAB Central File Exchange, www.mathworks.co.uk/matlabcentral/fileexchange). Two investigators (O. Linares Perdomo and D.S. Collingridge) independently confirmed the Malagasy
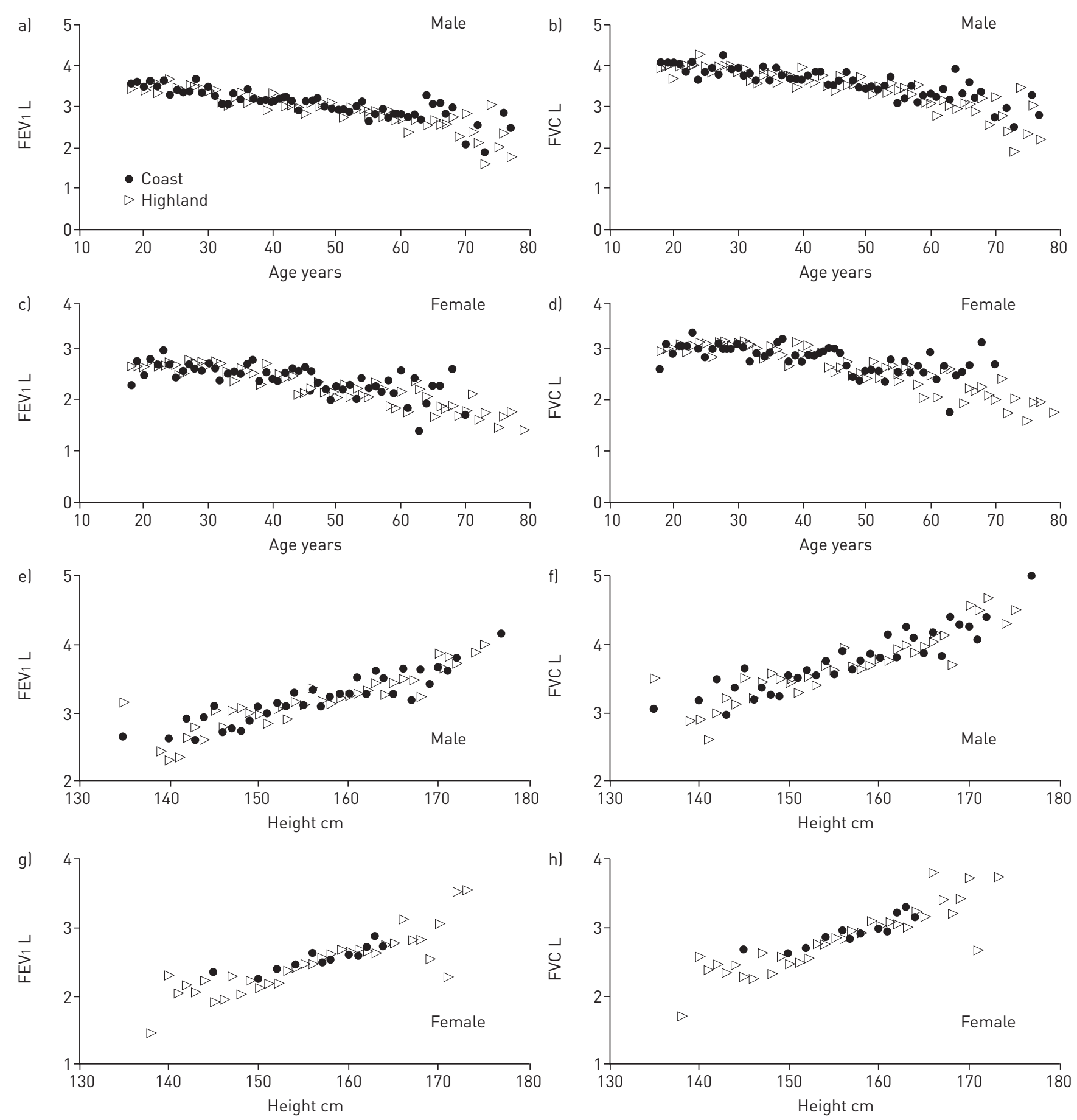

FIGURE 2 Mean forced expiratory volume in $1 \mathrm{~s}(\mathrm{FEV} 1$ ) and mean forced vital capacity (FVC) versus a-d) age and e-h) height for male and female Malagasy coast and highland dwellers. 
TABLE 2 Prediction equations for adult Malagasy males and females aged 18-73 years

\begin{tabular}{|c|c|c|c|}
\hline Parameter & Prediction equation & SDresiduals & $1.64 \times$ SDresiduals \\
\hline \multicolumn{4}{|l|}{ Males } \\
\hline FEV $1 \mathrm{~L}$ & $3.16624 \mathrm{H}-0.02008 \mathrm{~A}-1.30086$ & 0.39 & 0.65 \\
\hline $\mathrm{FEV}_{1} / \mathrm{FVC} \%$ & $-0.07029 A+88.81584$ & 5.66 & 9.29 \\
\hline \multicolumn{4}{|l|}{ Females } \\
\hline FEV 1 L & $3.25608 \mathrm{H}-0.01571 \mathrm{~A}-2.02193$ & 0.32 & 0.53 \\
\hline FVC L & $3.88087 \mathrm{H}-0.01513 \mathrm{~A}-2.63796$ & 0.37 & 0.61 \\
\hline
\end{tabular}

Lower limit of normal (5th percentile) is estimated as predicted-(1.645xsDresiduals). sDresiduals: standard deviation of the difference between measured and predicted values; FEV1: forced expiratory volume in $1 \mathrm{~s}$; FVC: forced vital capacity; H: height in metres; A: age in years.

TABLE 3 Differences between individual Malagasy measured values and predictions for FEV1, FVC and FEV1/FVC

\begin{tabular}{|c|c|c|c|c|c|c|}
\hline \multirow{2}{*}{$\begin{array}{l}\text { Parameter } \\
\text { difference }\end{array}$} & \multirow[t]{2}{*}{ Study } & \multirow[t]{2}{*}{ Group } & \multicolumn{2}{|c|}{ Males } & \multicolumn{2}{|c|}{ Females } \\
\hline & & & $\begin{array}{c}\text { Mean of individual } \\
\text { subject } \\
\text { differences } \#\end{array}$ & $\begin{array}{l}\text { Absolute } \\
\text { difference }\end{array}$ & $\begin{array}{c}\text { Mean of individual } \\
\text { subject } \\
\text { differences } \#\end{array}$ & Absolute \\
\hline \multirow[t]{8}{*}{$\mathrm{FEV}_{1} \mathrm{~L}$} & QUANJER [3] & ECSC & -10.80 & 0.11 & -6.22 & 0.06 \\
\hline & HANKINSON [2] & Caucasian & -13.95 & 0.14 & -12.98 & 0.13 \\
\hline & QuANJer [4] & Caucasian? & -14.39 & 0.14 & -12.42 & 0.12 \\
\hline & & Black $^{+}$ & 2.41 & 0.02 & 3.08 & 0.03 \\
\hline & & North East Asian $\S$ & -10.45 & 0.10 & -10.75 & 0.11 \\
\hline & & South East Asian ${ }^{f}$ & -4.79 & 0.05 & 0.37 & 0.00 \\
\hline & & Other $\# \#$ & -6.58 & 0.06 & -4.73 & 0.05 \\
\hline & This study & Malagasy & 0.71 & 0.00 & 0.50 & 0.00 \\
\hline \multirow{6}{*}{ FVC L } & QuANJer [4] & Caucasian & -19.90 & 0.20 & -16.23 & 0.16 \\
\hline & & Black $^{+}$ & -1.32 & 0.01 & 0.51 & 0.05 \\
\hline & & North East Asian $\S$ & -15.14 & 0.15 & -13.22 & 0.13 \\
\hline & & South East Asian ${ }^{f}$ & -6.58 & 0.06 & 0.12 & 0.00 \\
\hline & & Other \#\# & -10.40 & 0.10 & -6.94 & 0.07 \\
\hline & This study & Malagasy & 0.53 & 0.00 & 0.53 & 0.01 \\
\hline \multirow[t]{7}{*}{$\mathrm{FEV}_{1} / \mathrm{FVC} \%$} & QUANJeR [3] & ECSC & -9.20 & 0.09 & -9.35 & 0.09 \\
\hline & HANKINSON [2] & Caucasian & 7.18 & 0.07 & 4.49 & 0.04 \\
\hline & & Mexican-American & -9.45 & 0.09 & -9.67 & 0.09 \\
\hline & & African-American & 7.44 & 0.07 & 7.80 & 0.08 \\
\hline & QUANJer [4] & Caucasian? & 4.64 & 0.05 & 3.10 & 0.03 \\
\hline & & Black $^{+}$ & $\begin{array}{l}4.04 \\
3.88\end{array}$ & 0.04 & 2.56 & 0.03 \\
\hline & & North East Asian $\S$ & 4.11 & 0.04 & 2.24 & 0.02 \\
\hline
\end{tabular}

FEV1: forced expiratory volume in 1 s; FVC: forced vital capacity; ECSC: European Community for Steel and Coal. " : observed-predicted; I: people from Europe, Israel, Australia, USA, Canada, Brazil, Chile, Mexico, Uruguay, Venezuela, Algeria and Tunisia, and Mexican-Americans;

${ }^{+}$: equivalent to African-American, with data exclusively from the USA population collected for the MESA (Multi-Ethnic Study of Atherosclerosis) lung study [8], NHANES (National Health and Nutrition Examination Survey) III [2], NHANES IV [9] and the study by WANG et al. 10; ${ }^{\S}$ : Korea and China north of the Huaihe River and Qinling Mountains; ${ }^{f}$ : Thailand, Taiwan and China south of the Huaihe River and Qinling Mountains; \#\#: individuals not represented by the other four groups in the study by QUANJER et al. [4]. 
prediction equations and the Z-score computations by independently checking the computer code and duplicating the results.

For comparison purposes, we created male and female FEV1, FVC and FEV1/FVC prediction equations following the GAMLSS approach $[6,7,12]$. We excluded outliers that were at least four standard deviations from the mean (i.e. Z-score of \pm 4 ) from the GAMLSS modelling process. Next, we searched for the most parsimonious models by evaluating log-log plots, adding penalised smoothing splines, altering distributions with a log link function (e.g. Box Cox Cole Green, Box Cox Power Exponential), adding log transformations on age and height, and fixing the shape parameter (nu) to 1. Using the Schwarz Bayesian Criteria with a penalty function to prevent over-fitting, we selected the most parsimonious GAMLSS models then created splines, lookup tables, predicted values and standardised residuals for these models.

\section{Results}

The questionnaire was completed by 4526 subjects (fig. 1). Questionnaire responses excluded 1519 subjects, leaving 3007 who provided spirograms. A total of 516 subjects with spirograms (17.2\% of 3007) were excluded from analysis, with 102 being excluded because they could not perform acceptable or repeatable spirograms and a further 414 being excluded for undocumented reasons after review by a pulmonologist. The final study cohort included 1063 (43\%) females and 1428 (57\%) males (table 1 and
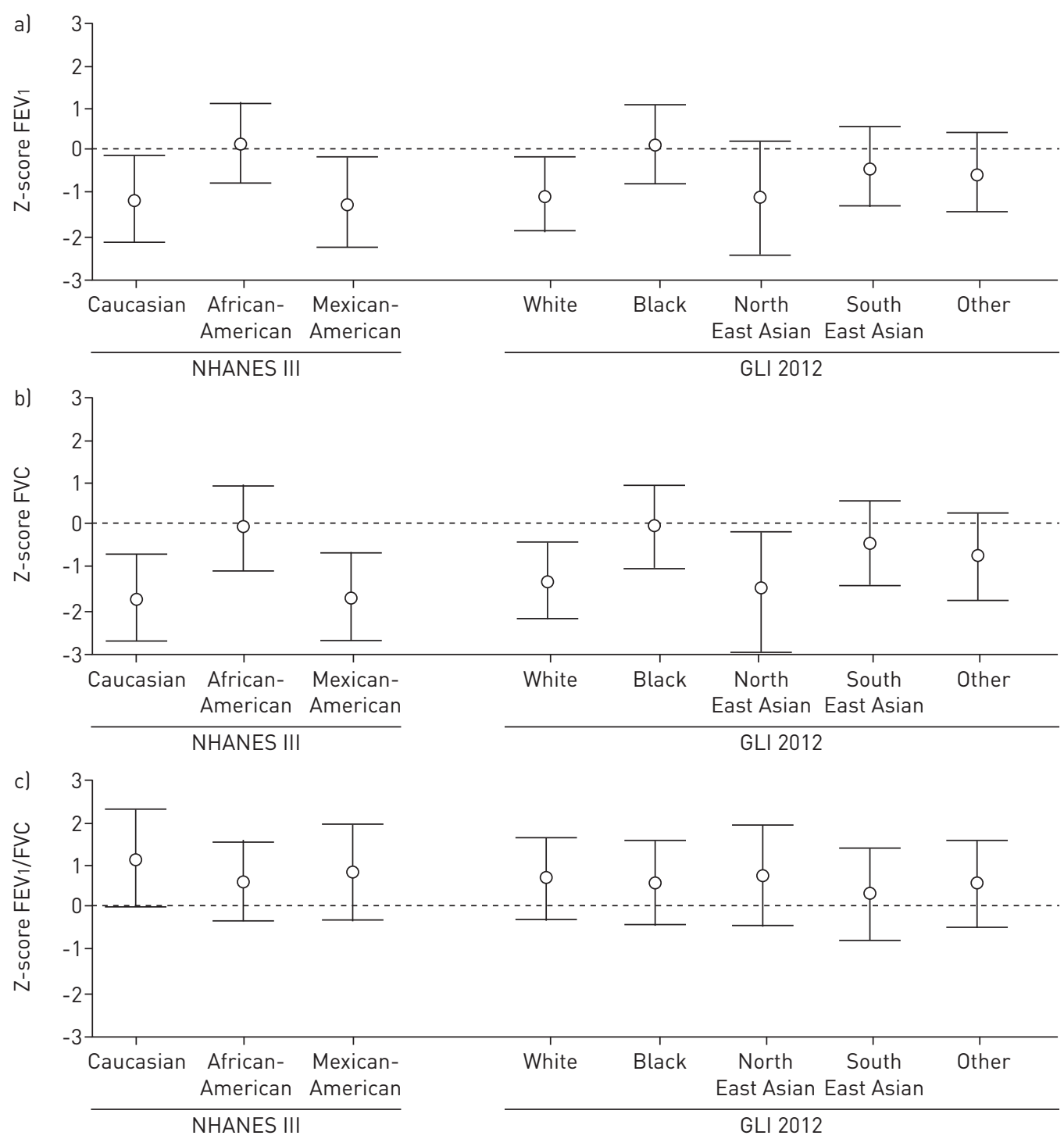

FIGURE 3 Z-scores for a) forced expiratory volume in $1 \mathrm{~s}$ (FEV1), b) forced vital capacity (FVC) and c) FEV1/FVC ratio between observed Malagasy values and predicted values using the third National Health and Nutrition Examination Survey (NHANES III) [2] and Global Lung Function Initiative (GLI) 2012 [4] predictions for males. Z-scores were calculated as (observed-predicted)/sDpred, where sDpred is the standard deviation of the predicted value. 
fig. 1). Aggregate values for FEV1, FVC, FEV1/FVC ratio, PEF, FEF25\%, FEF50\%, FEF75\% and FEF25-75\% for male and female coast and highland dwellers are shown in supplementary table S1. The coast and highland Malagasy subjects had similar mean FEV1 and FVC values and similar regression equations across the entire age and height range (fig. 2). Small differences in very old subjects did not justify separate regressions and we treated all subjects as members of one homogeneous population.

Age and height were independent variables for all spirometry parameters except FEV1/FVC (for which only age was an independent variable). Male and female prediction equations for FEV1, FVC and FEV1/ FVC are shown in table 2 . We computed the LLN of the population as the predicted-(1.645×SDresiduals). Prediction equations for the other parameters are shown in supplementary table S2.

The GAMLSS residuals were compared with the multiple linear regression analysis residuals (supplementary table S4). The GAMLSS models were not superior to the multiple linear regression models. The likely reason for lack of improvement with GAMLSS modelling is that our Malagasy data are largely linear for individuals aged 18-73 years (fig. 2). Finally, a dichotomous variable representing elevation (highland versus coastal) added to the GAMLSS model was not a significant predictor of FEV1, FVC and FEV1/FVC. For this reason we excluded elevation from our GAMLSS prediction equations.
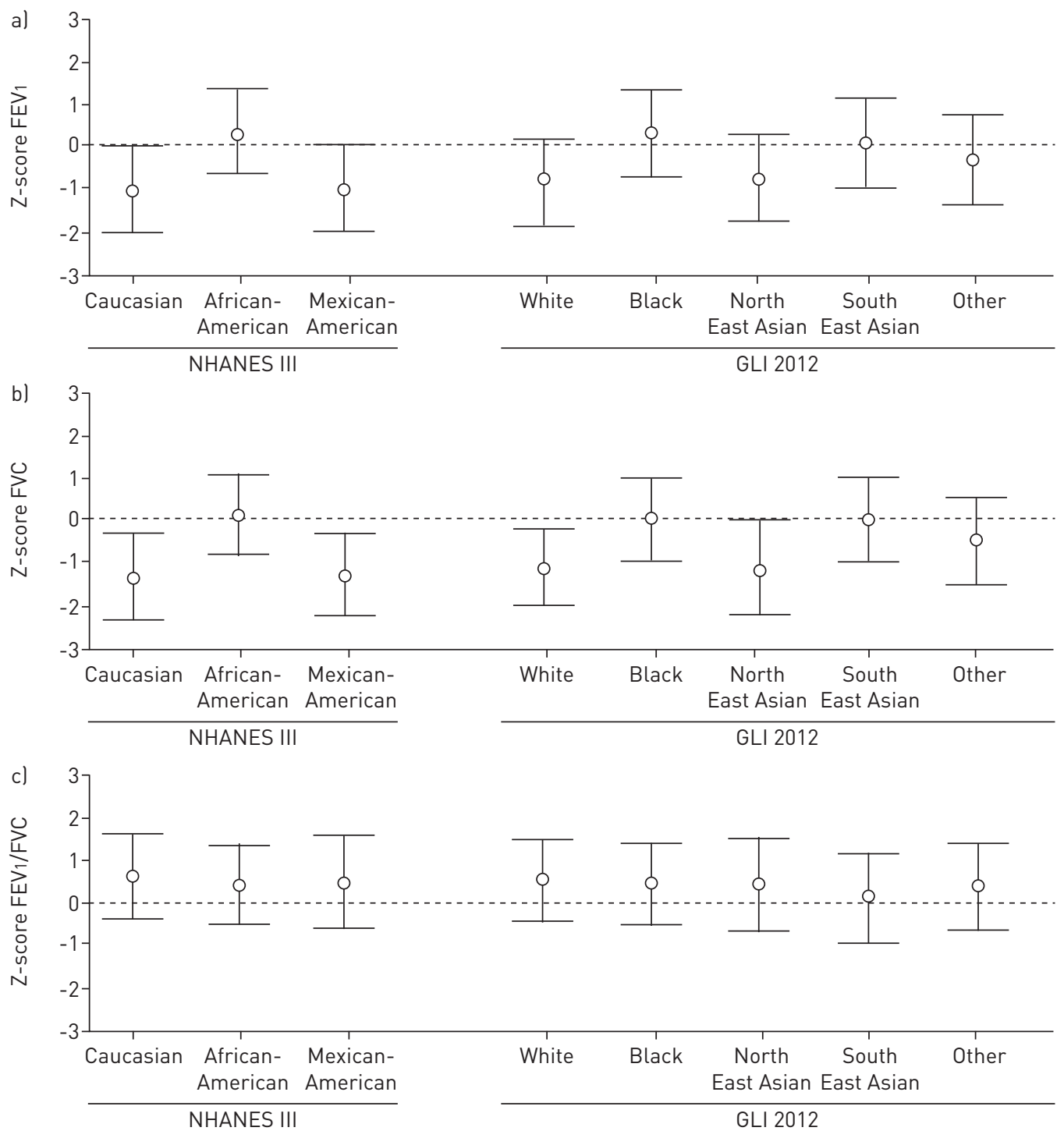

FIGURE 4 Z-scores for a) forced expiratory volume in $1 \mathrm{~s}$ (FEV1), b) forced vital capacity (FVC) and c) FEV1/FVC ratio between observed Malagasy values and predicted values using the third National Health and Nutrition Examination Survey (NHANES III) [2] and Global Lung Function Initiative (GLI) 2012 [4] predictions for females. Z-scores were calculated as (observed-predicted)/sDpred, where sDpred is the standard deviation of the predicted value. 
Comparisons of our data, and the Malagasy multiple linear regression model, with ECSC, NHANES III and GLI 2012 models are presented in table 3 and supplementary table S3. Z-scores comparing our observed Malagasy spirometry data with published prediction equations are shown in figures 3 and 4 .

\section{Discussion}

This study contains important attributes needed for the development of clinically useful reference equations for the Malagasy population, although the study subjects were not randomly selected from the population. The reference subjects were derived from a large sociodemographically representative population, distributed with regard to sex, age, height and ethnic background (highland versus coast dwellers). The population included only life-long nonsmokers and patients without overt cardiac or pulmonary disease. Because spirometry tracings were not saved for independent quality review, it is not possible to determine whether all tests met current ATS/ERS standards (a pulmonologist excluded spirograms of 414 subjects for reasons that were not recorded). However, given the absence of previous data for spirometry prediction equations for Malagasy subjects, the current results provide the best approximate estimate of spirometry predictions for residents of Madagascar. Future studies should further improve our prediction equations. We cannot comment on extrapolation of these reference equations beyond the age range (18-73 years) of our Malagasy data.

We chose to report the simpler multiple linear regression models because the GAMLSS and linear regression models for adults were clinically indistinguishable. We only studied adult subjects aged 18-73 years, an age range that avoids the changes in lung function due to the growing lungs of children.

Comparisons of our measurements with published prediction equations revealed that Malagasy FEV1, FVC and FEV1/FVC can be most accurately predicted, in the aggregate, by NHANES III African-American prediction equations for males and females (table 3 and figs 3 and 4), and by GLI 2012 black predictions for males and black and South East Asian predictions for females (table 3 and figs 3 and 4). ECSC-predicted FEV1 and FVC were poorly matched to Malagasy measurements (table 3).

\section{Conclusion}

Within study constraints, we provide the first spirometry reference equations for a healthy adult Malagasy population and the first comparison of Malagasy population measurements with ECSC, NHANES III and GLI 2012 prediction equations. Our study was carried out in a sociodemographically representative population sample. These reference equations are the best available for clinical practice and epidemiological studies in Madagascar. Interestingly, the NHANES III African-American and GLI 2012 black and South East Asian prediction equations (not the "other" group prediction equations) are best matched to Malagasy subjects, regardless of ethnic background.

\section{Acknowledgements}

This work was a collaboration between the MaSpiroGroup in Madagascar and the Groupe de Travail des Normes Spirométriques Malgaches (NSM), Pneumalga, France. Members of these groups are as follows. MaSpiroGroup, Madagascar: F. Rakotosihanaka, H. Randrianary, J. Rafaliarisoa and M. Randriantahiry (Centre Hospitalo Universitaire Fenoarivo); R. Andriamihaja and R. Razafinjato (Centre Hospitalier Universitaire de Toamasina); J.M. Ramonja, L. Raholiarisoa and H. Razafiarison (Centre hospitalier de Référence Régional Fianarantsoa); and R. Rakotovao (Clinique Saint-Luc, Toliara). Groupe de Travail des Normes Spirométriques Malgaches, Pneumalga, France: O. Randrianarivelo (Exploration Fonctionnelle Respiratoire Groupe Hospitalier Pitié-Salpêtrière, Paris), D. Rakotonanahary (Hôpital Saint Antoine, Paris), F. Rasolojaona (Cabinet Medical, Provins) and J. Ratomaharo (Service de Pneumologie, Hôpital Privé d'Athis-Mons, Athis-Mons).

\section{References}

1 Pellegrino R, Viegi G, Brusasco V, et al. Interpretative strategies for lung function tests. Eur Respir J 2005; 26 : 948-968.

2 Hankinson JL, Odencrantz JR, Fedan KB. Spirometric reference values from a sample of the general US population. Am J Respir Crit Care Med 1999; 159: 179-187.

3 Quanjer PH, Tammeling GJ, Cotes JE, et al. Lung volumes and forced ventilatory flows. Report Working Party Standardization of Lung Function Tests, European Community for Steel and Coal. Official Statement of the European Respiratory Society. Eur Respir J 1993; 6 Suppl. 16:5-40.

4 Quanjer PH, Stanojevic S, Cole TJ, et al. Multi-ethnic reference values for spirometry for the 3-95-yr age range: the global lung function 2012 equations. Eur Respir J 2012; 40: 1324-1343.

5 Quanjer PH, Hall GL, Stanojevic S, et al. Age- and height-based prediction bias in spirometry reference equations. Eur Respir J 2012; 40: 190-197.

6 Rigby RA, Stasinopoulos DM. Generalized additive models for location, scale and shape. J R Stat Soc Ser C Appl Stat 2005; 54: 507-554.

7 Stasinopoulos DM, Rigby RA. Generalized additive models for location scale and shape (GAMLSS) in R. J Stat Softw 2007; 23: i07.

8 Hankinson JL, Kawut SM, Shahar E, et al. Performance of American Thoracic Society-recommended spirometry reference values in a multiethnic sample of adults: the multi-ethnic study of atherosclerosis (MESA) lung study. Chest 2010; 137: 138-145. 
9 National Health and Nutrition Examination Survey IV(NHANES IV). Hyattsville, National Center for Health Statistics Data Dissemination Branch. http://clinicaltrials.gov/show/NCT00005154 Date last updated: April 13, 2009.

10 Wang X, Dockery DW, Wypij D, et al. Pulmonary function between 6 and 18 years of age. Pediatr Pulmonol 1993; 15: 75-88.

11 Human Development Report 2013. The Rise of the South: Human Progress in a Diverse World. New York, United Nations Development Programme, 2013. Available from: www.undp.org/content/undp/en/home/ librarypage/hdr/human-development-report-2013/.

12 Quanjer PH, Stanojevic S, Stocks J, et al. GAMLSS in action: annotated examples of working with $\mathrm{R}$ and GAMLSS. Global Lung Function Initiative, 2012. Available from: www.lungfunction.org/gamlss.html 